\title{
Effects of Grape Seedlings Intercropping with Bidens Species on Soil Organic Matter and Soil Enzyme Activity under Cadmium Stress
}

\author{
Dan Xia ${ }^{1, a}$, Lijin Lin ${ }^{2, b}$, Xinxin Li ${ }^{1, c}$ and Ming'an Liao ${ }^{1, d^{*}}$ \\ ${ }^{1}$ College of Horticulture, Sichuan Agricultural University, Chengdu, Sichuan, China \\ ${ }^{2}$ Institute of Pomology and Olericulture, Sichuan Agricultural University, Chengdu, Sichuan, China

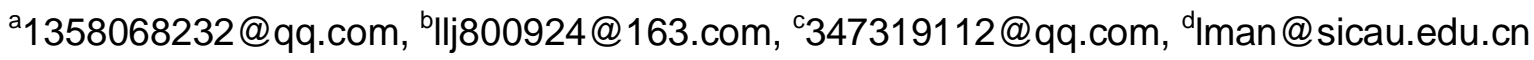 \\ ${ }^{*}$ Corresponding author. Dan Xia and Lijin Lin contributed equally to this work.
}

Keywords: Intercropping; Grape; Photosynthesis; Soil enzyme activity; Bidens species.

Abstract: The effects of intercropping with four Bidens species (Bidens bipinnata, Bidens pilosa, Bidens parviflora and Bidens biternata) with grape seedlings on soil organic matter and soil enzyme activity under cadmium (Cd) stress were examined in order to provide the reference for grape production in cadmium pollution area. The results showed that intercropping treatments could increase the organic matter content in soil. In addition, intercropping treatments could increase the soil urease, invertase and catalase activities. Compared with monoculture, Intercropping with Bidens species decreased the soil phosphatase activity except $B$. parviflora. Therefore, soil enzyme activity and organic matter content could be increased by intercropping under cadmium stress, and the best material was $B$. parvifora.

\section{Introduction}

With the development of economy and urbanization process, soil heavy metal pollution has become a worldwide problem [1]. Cd is one of the most toxic heavy metal which will endanger the growth and development of plants and ultimately affect human health [2-3]. In recent years, the farmland soil was polluted by heavy metal, orchard was polluted by cadmium gradually [4]. Grape is a worldwide important fruit and the production occupies a pivotal position of fruit [5-6], and it also could be polluted by $\mathrm{Cd}$ [7]. In agricultural production, intercropping treatments can not only increased the effective utilization of soil nutrients, but also increased crop yield and soil enzyme activity [8-10]. In addition, intercropping Bidens species can effectively reduce Cd stress on fruit tree and increase the absorption of organic matter in Cd contaminated soil [11-13]. The rhizosphere effects occur in plants when intercropping to make a series of changes of physiology and biochemistry under heavy metal stress [14]. Therefore, in this study, four Bidens species (Bidens bipinnata, Bidens pilosa, Bidens parviflora and Bidens biternata) were used to intercrop with grape seedlings under $\mathrm{Cd}$ stress, and the effects of grape seedlings intercropping with Bidens species on soil organic matter soil enzyme activity were studied. The aim of this study was to screen out the best Bidens species which could promote the organic matter content in soil and soil activities of grape.

\section{Materials and Methods}

Materials. In April 2016, the seeds of four Bidens species (B. bipinnata, B. pilosa, B. parviflora and $B$. biternata) were collected from the surrounding farmland at Chengdu campus of Sichuan Agricultural University. Then, the seeds were put in the climate chamber to germination and further cultivation and transplanting. The species of the experimental cultivar of grape is Kyoho whose cutting seedlings were purchased from Longquanyi area seedlings base of Chengdu in May 2016. The soil for the experiment was collected from the surrounding farmland at Chengdu campus of Sichuan Agricultural University in April 2016.

Experimental Design. The experiment was conducted in Chengdu Campus of Sichuan Agricultural University from April to July 2016. In April 2016, the soil was air-dried and passed through a 6.72-mm sieve. $3 \mathrm{~kg}$ air-dried soil was weighed into each plastic pot $(21 \mathrm{~cm} \mathrm{high,} 20 \mathrm{~cm}$ 
in diameter), soaking uniformly by $5 \mathrm{mg} / \mathrm{kg} \mathrm{Cd}$ (in the form of $\mathrm{CdCl}_{2} \cdot 2.5 \mathrm{H}_{2} \mathrm{O}$ ) solution for 4 weeks. All pots were watered each day to keep the soil moisture about 80\%. In May 2016, three uniform-sized cutting seedlings (the shoots were about $15 \mathrm{~cm}$ ) of Kyoho grape were transplanted into pot for monoculture. Two uniform-sized seedlings (two true leaves expanded) of each four hyperaccumulators and two grape seedlings were transplanted into each pot for intercropping. For each treatment with three replicates and the pots placed completely random. The distance between pots was $15 \mathrm{~cm}$, and the pot position exchanged aperiodically to weaken the impact of the marginal effects. The soil moisture content was maintained at $80 \%$ of field capacity until the plants were harvested.

After 60 days, the soil in the $0-5 \mathrm{~cm}$ layer of each pot was taken out, mixed and packaged in plastic bags and brought back to the laboratory and stored in a refrigerator at 4 degrees centigrade. Soil enzyme activity was determined by soil enzyme method after soil $1 \mathrm{~mm}$ screening. The activity of catalase was expressed as the volume of $0.02 \mathrm{~mol} / \mathrm{L} \mathrm{KMnO}_{4}$ per gram of soil at room temperature in 30 minute. Soil urease activity was expressed in grams $(\mathrm{mg})$ of $\mathrm{NH}^{3+}-\mathrm{N}$ per gram of soil at $37^{\circ} \mathrm{C}$ for 24 hours. Soil invertase activity was expressed in the amount of glucose released per gram of soil at $37^{\circ} \mathrm{C}$ for 24 hours. Soil phosphatase was expressed in grams of phenol per gram of soil.

Statistical Analyses. Statistical analyses were conducted using statistical software of SPSS 17.0. Date were analyzed by one-way ANOVA with least significant difference at $5 \%$ confidence level.

\section{Results and Discussion}

Soil Organic Matter. Compared with the monoculture, intercropping with four Bidens species increased the organic matter content in soil under $\mathrm{Cd}$ stress (Fig. 1). The content organic matter in soil were ranked in the following order: intercropping with $B$. parvifora $>$ intercropping with $B$. biternata $>$ intercropping with $B$. pilosa > intercropping with $B$. bipinnata > monoculture. When intercropped with $B$. bipinnata, B. pilosa and $B$. biternata the soil organic matter increased by $3.71 \%(p<0.05), 18.96 \%(p<0.05)$ and $22.94 \%(p>0.05)$ respectively compared with the monoculture, indicating that intercropping with Bidens species could promote the organic matter content in soil under Cd stress, and intercropping with $B$. parviflora could most effectively promote the content organic matter, which increased by $93.87 \%(p<0.05)$.

Phosphatase activity. Grape seedlings intercropping with four Bidens species had the differents influence for soil phosphatase activity under Cd stress (Fig. 2). Compared with the monoculture, the soil phosphatase activity increased significantly by intercropping with $B$. parvifora under $\mathrm{Cd}$ stress, which was improved by $9.92 \%(p<0.05)$. But grape seedlings intercropping with $B$. bipinnata, B. pilosa and B. biternata decreased the soil phosphatase activity, which were decreased by $21.36 \%(p<0.05), 10.06 \%(p<0.05)$ and $29.52 \%(p<0.05)$ respectively .

Urease Activity. Compared with the monoculture, intercropping with four four Bidens species ( $B$. bipinnata, B. pilosa, B. parviflora and B. biternata) increased the soil urease activity under $\mathrm{Cd}$ stress (Fig. 3, $p>0.05$ ). The urease activity of soil by intercropping with B.bipinnata, B. pilosa, B. 
parviflora and B. biternata increased by $6.19 \%, 1.64 \%, 12.62 \%$ and $3.79 \%$ respectively compared to monoculture.

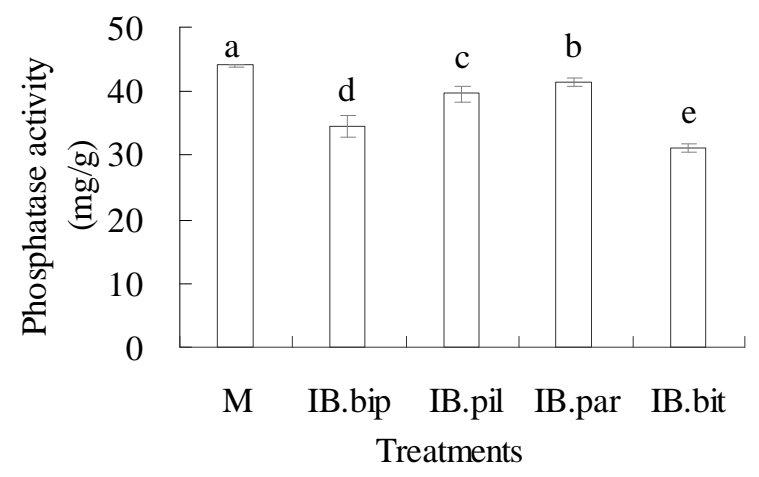

Fig. 2 Soil phosphatase activity. Different lowercase letters indicate significant differences based on one-way analysis of variance in SPSS 17.0 followed by the least significant difference test $(p<0.05) . \mathrm{M}=$ monoculture, $\mathrm{I}$ B.bip $=$ intercropping with $B$. bipinnata, $\mathrm{I} B$.pil $=$ intercropping with $B$. pilosa, IB.par = intercropping with $B$. parviflora, IB.bit = intercropping with $B$. biternata.

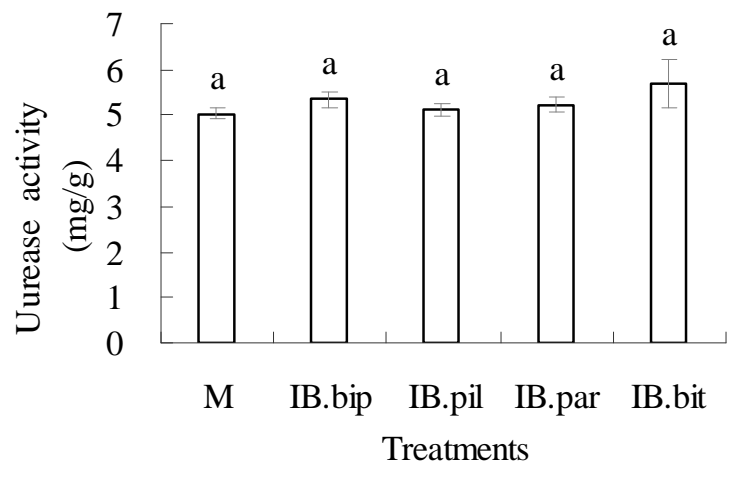

Fig. 3 Soil urease activity. Different lowercase letters indicate significant differences based on one-way analysis of variance in SPSS 17.0 followed by the least significant difference test $(p<0.05) . \quad \mathrm{M}=$ monoculture, $\mathrm{I}$ B.bip $=$ intercropping with $B$. bipinnata, IB.pil = intercropping with $B$. pilosa, IB.par = intercropping with $B$. parviflora, $\mathrm{I}$ B.bit $=$ intercropping with $B$. biternata.

Invertase activity. The changes of soil invertase activity got a significant level by intercropping compared with the monoculture (Fig. $4, p<0.05$ ). The soil invertase activity of intercropping significantly increased compared with the monoculture. The soil invertase activities were ranked in the following order: intercropping with $B$. pilos $>>$ intercropping with $B$. parviflora $>$ intercropping with $B$. biternata $>$ intercropping with $B$. bipinnata $>$ monoculture. When grape seedlings intercropped with B. bipinnata, B. pilosa, B. parviflora and B. biternata, the invertase activity increased by $5.56 \%, 18.95 \%, 14.79 \%$ and $7.76 \%$ respectively compared with the monoculture.

Catalase activity. Compared with the monoculturethe, activitiy of catalase in soil increased significantly by intercropping with $B$. pilosa and $B$. parvifora under $\mathrm{Cd}$ stress, which increased respectively by $38.56 \%$ and $40.28 \%$. Compared with intercropping with $B$. pilosa and $B$. parvifora, intercropping with $B$. bipinnata and $B$. biternata had little effect on the soil catalase activity, only incresed by $11.84 \%$ and $14.98 \%$.

\section{Conclusions}

Under cadmium stress, the organic matter content in soil and soil urease, invertase and catalase activities could be increased significantly by intercropping with four Bidens species. But Intercropping with $B$. bipinnata, B. pilosa and B. biternata decreased the phosphatase activity, and it shows that the three kinds of plant restrained the phosphatase activities in soil. Intercropping with B. parvifora not only increased the content organic matter in soil but also increased the soil enzyme activity. Therefore, under cadmium stress, soil enzyme activity and soil organic matter could be increased by intercropping, and the best material was B. parvifora, and followed by B. pilosa.

\section{Acknowledgements}

This work was financially supported by the Application Infrastructure Project of Science and Technology Department of Sichuan Province (2016JY0258). 

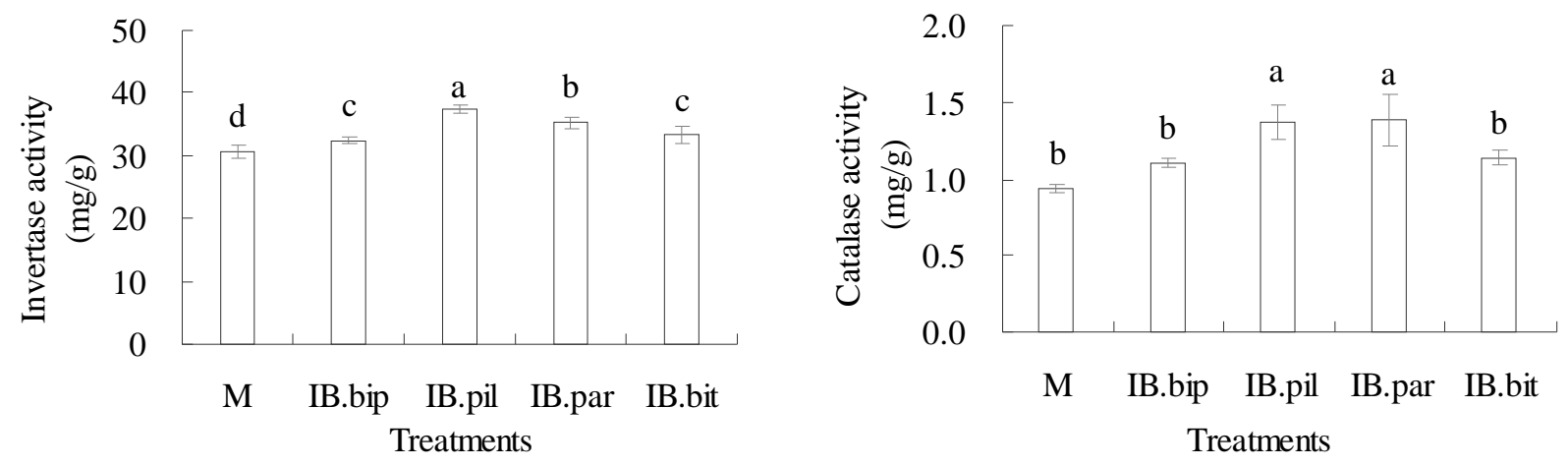

Fig. 4 Soil invertase activity. Different Fig. 5 Soil catalase activity. Different lowercase lowercase letters indicate significant differences letters indicate significant differences based on based on one-way analysis of variance in SPSS one-way analysis of variance in SPSS 17.0 17.0 followed by the least significant difference followed by the least significant difference test test $(p<0.05) . \mathrm{M}=$ monoculture, $\mathrm{I}$ B. bip $=(p<0.05) . \mathrm{M}=$ monoculture, $\mathrm{I}$ B. bip $=$ intercropping with $B$. bipinnata, IB.pil = intercropping with B. bipinnata, IB.pil = intercropping with $B$. pilosa, IB.par $=$ intercropping with $B$. pilosa, IB.par = intercropping with $B$. parviflora, $\mathrm{I}$ B.bit $=$ intercropping with $B$. parviflora, $\mathrm{I}$ B.bit $=$ intercropping with $B$. biternata. intercropping with $B$. biternata.

\section{References}

[1] M. Neetu and A.K. Biswas: Scientific Reviews \& Chemical Communications Vol. 2 (2012), p. 141.

[2] J.B. Zhang and W.N. Huang: Journal of ecology Vol. 20 (2000), p. 514.

[3] H. Tang, T.X. Li, Z.X. Zhou, H.Y. Yu and G.D. Chen: Journal of Agro-Environment Science Vol. 34 (2015), p. 471.

[4] J.T. Li, J.W. Qiu and X.W. Wang: Environment Pollution Vo1. 143 (2006), p. 159.

[5] D. Tian, J.Y. Feng, X. Chen and W.S. Mu: World Agriculture Vol. 6 (2010), p. 46.

[6] M.N. Chen, M.F. Guan, C.L. Hu and M.C. Li: Southern Agricultural Machinery Vol. 1 (2016), p. 20.

[7] Y.X. Su, S. J. Wang, L.W. Zhao and Q.B. Chen: Tianjin Agricultural Sciences Vol. 22 (2016), p. 20.

[8] J.Shi, T.Y. Huang, X.D. Zhu and L.J. Lin: Shanxi Agricultural Sciences Vol. 61 (2015), p. 28.

[9] Ahmad I, Z. Cheng and H. Meng: Pakistan Journal of Botany Vol. 45 (2013), p. 695.

[10] L. Li, X.L. Li, F.S. Zhang, J.H. Sun, S.C. Yang and M.J. Lu: Plant Nutrition and Fertilizer Science Vol. 6 (2000), p. 140.

[11] S.H. Wei, C.J. Yang and Q.X. Zhou: Environmental Science Vol. 29 (2008), p. 2912.

[12] L.L. Dong, X.G. Zhao, S.J. Zhang, Y.H. Zhang, N. Liang and Y.M. Zhao: Chinese Journal of Soil Science Vol. 40 (2009), p. 374.

[13] Y.B. Sun, Q.X. Zhou, L. Wang, W.T. Liu and R. Liu: Environmental Science Vol. 30 (2009), p. 3028 .

[14] C.J. Li, W. Ma and F.S. Zhang: Plant Nutrition and Fertilizer Science Vol. 14 (2008), p. 178. 